\title{
Effects of food deprivation and initial levels on a wheel-running response to methamphetamine*
}

\author{
LEONARD F. JAKUBCZAK \\ Gerontological Psychology Research Laboratory \\ VA Hospital, St. Louis, Mo. 63125 \\ and \\ FRANK E. GOMER \\ Washington University, St. Louis, Mo. 63130
}

The purpose of this experiment was to determine the time course and peak effects of methamphetamine on wheel-running activity of food-deprived rats and to determine whether degree of food deprivation and/or predeprivation levels interact with dosage to influence running activity. The experiment was carried out according to a 4 by 3 by 2 by 5 design, representing four dosage levels of methamphetamine $\mathrm{HCl}(0.00,0.75$, 1.50 , and $3.00 \mathrm{mg} / \mathrm{kg}$ ), three food-deprivation conditions ( $90 \%, 80 \%$, and $70 \%$ of ad lib body weight), two blocks of rats formed on the basis of predeprivation levels of running, and five hourly samples of running activity. The results indicated that the peak effects of methamphetamine on running activity occur with a dose of $1.50 \mathrm{mg} / \mathrm{kg}$, during the first hour after injection, and are additive to the effects of food deprivation and predeprivation running levels.

The general stimulating effect of amphetamine on bodily activity of rats and mice is well established (Cole, 1970). However, this generalization must be qualified by considerations of drug-dosage control levels of activity (Cole, 1970; Irwin, Slabok, \& Thomas, 1958), as well as degree of food deprivation (Cole, 1965; Fibiger \& Campbell, 1971). How the effects of these variables on activity-wheel running combine when presented simultaneously is not known. Consequently, the present investigation was undertaken in order to: (a) determine the time course and peak effects of four dosage levels of subcutaneously injected methamphetamine on wheel running (RA) of food-deprived rats and (b) determine whether degree of food deprivation and/or initial levels interact with dosage level to influence wheel-running activity.

\section{METHOD}

Subjects

Forty-eight naive male Sprague-Dawley rats (Holtzman, Madison, Wisconsin), 84 days old at the start of the experiment, were used. Just prior to deprivation, their weight was $404.4 \mathrm{~g}$ $(\mathrm{SD}=19.3)$.

Design
The experiment was carried out according to a 4 by 3 by 2 by 5 design (Winer, 1971, Case II), representing four dosage levels of methamphetamine $\mathrm{HCl}(0.00,0.75,1.50$, and

*This investigation was supported by 821 Funds of the U.S. Veterans Administration (MRIS 0150-02) and was carried out during the second author's tenure as VA Trainee in Psychology (experimental and physiological) at Washington University.
$3.00 \mathrm{mg} / \mathrm{kg})$, three food-deprivation conditions $(90 \%, 80 \%$, and $70 \%$ of ad lib body weight), two blocks of rats formed on the basis of amounts of running during the 3 days prior to initiation of the deprivation schedules (predeprivation activity levels), and five hourly samples of RA. The dependent variable was the number of wheel revolutions emitted during each successive hour of the experiment.

\section{Procedure}

The rats were assigned randomly to Wahmann activity wheels, with food and water available ad lib in the living compartments. The animals were locked in the wheel drums for $6 \mathrm{~h}$ each day. At the end of $6 \mathrm{~h}$ they were removed, weighed, and locked in the living compartments for the remaining $18 \mathrm{~h}$. The procedure was followed for 14 days to allow assessment of pretreatment activity levels. On the 15 th day, the rats were assigned randomly to one of the three food-deprivation conditions designed to maintain them at $90 \%, 80 \%$, or $70 \%$ of their average weight during the previous 3 days. Again, at the end of $6 \mathrm{~h}$ the rats were removed from the wheels, weighed, and locked in the living compartments. Water remained available ad lib, and $1 \mathrm{~h}$ after removal from the drums the animals received the appropriate food ration. Twenty-one days were allowed to stabilize body weights and daily wheel revolutions. To eliminate the depressant effect that the injection per se might have on RA, the rats were adapted to the procedure of subcutaneous injection in the nape of the neck starting on the 35th day. The rats were locked in the drums at the regular time. Two hours later, they were briefly removed, injected with the appropriate volume of normal saline, based on a $1 \mathrm{cc} / \mathrm{kg} \mathrm{BW}$ ratio, returned to the drums, and locked in for the remaining $4 \mathrm{~h}$. Time of injection was between 10:00 a.m. and 1:00 p.m. and was randomized across treatment groups. Five days of adaptation to the injection procedure followed. On the 40th day, the rats were removed from the drums at the end of the second hour and were injected with the appropriate randomly assigned dosage level of methamphetamine (d-desoxyephedrine hydrochloride C-11, Arenol Chemical Corporation, Lot No. DE-1047, diluted in normal saline). Saline injections constituted the 0.00 dosage level. Immediately after injection, the rats were returned to the drums and locked in. The accumulated drum revolutions were recorded hourly. The data were analyzed by analysis of variance procedures using $\alpha<.05$ (Winer, 1971).

\section{RESULTS}

Table 1 presents the summary of the analysis of variance. Of prime interest is the significant Dose by Hours interaction $(\mathrm{p}<.05)$, which was independent of the effects of percent body weight and predeprivation activity levels (Fig. 1). Thus, averaging across predeprivation activity level and relative weight, only the $1.50 \mathrm{mg} / \mathrm{kg}$ methamphetamine group showed increased running above that of the $0.00 \mathrm{mg} / \mathrm{kg}$ group and only during the first hour after injection $(t=2.80$, $\mathrm{df}=70, \mathrm{p}<.01$, Satterthwarte approximate $\mathrm{t}$ test, Winer, 1971). There were no significant differences among the dose groups with respect to running during Hour 0 . The $0.00 / \mathrm{kg}$ group showed no increase in running between Hour 0 and Hour 1 but showed a significant increase in running between Hour 1 and 
Table 1

Analysis of Variance: Wheel Running as a Function of Dose of Methamphetamine, Relative Body Weight, Initial Level, and Hours

\begin{tabular}{lrrr}
\hline Source & df & Mean Squares & F \\
\hline Between Ss & 47 & & \\
Dose (A) & 3 & 126,260 & \\
Percent Body Weight (B) & 2 & $3,069,657$ & $16.53 \dagger$ \\
Initial Level (C) & 1 & $1,316,165$ & $7.09 \dagger$ \\
A by B & 6 & 284,105 & \\
B by C & 3 & 159,697 & \\
B by C & 2 & 13,161 & \\
A by B by C & 6 & 239,941 & \\
Ss Within Group & 24 & 185,662 & \\
Within Ss & 192 & & \\
Hours (D) & 4 & 192,197 & $5.04 \dagger$ \\
A by D & 12 & 73,963 & $1.94 *$ \\
B by D & 8 & 28,988 & \\
C by D & 4 & 58,348 & \\
A by B by D & 24 & 38,458 & \\
A by C by D & 12 & 64,697 & \\
B by C by D & 8 & 34,714 & \\
A by B by C by D & 24 & 47,584 & \\
D by Ss Within Group & 96 & 38,086 & \\
\hline
\end{tabular}

${ }^{*} p<.05 \quad t p<.01$

Hours 2, 3, and 4 . The latter $3 \mathrm{~h}$ did not differ among themselves with respect to revolutions.

The analysis of variance also indicated significant main effects of predeprivation activity $(p<.01)$, percent body weight $(p<.01)$, and hours $(p<.01)$ on wheel revolutions. Thus, averaging across dose, percent body weight, and hours, the group that had been more active prior to food deprivation ran significantly more during the test period than the group that had been less active. The respective means were 577.3 and $429.3 \mathrm{rph}$. Similarly, averaging across predeprivation activity levels, dose, and hours, the $90 \%$ weight group ran significantly

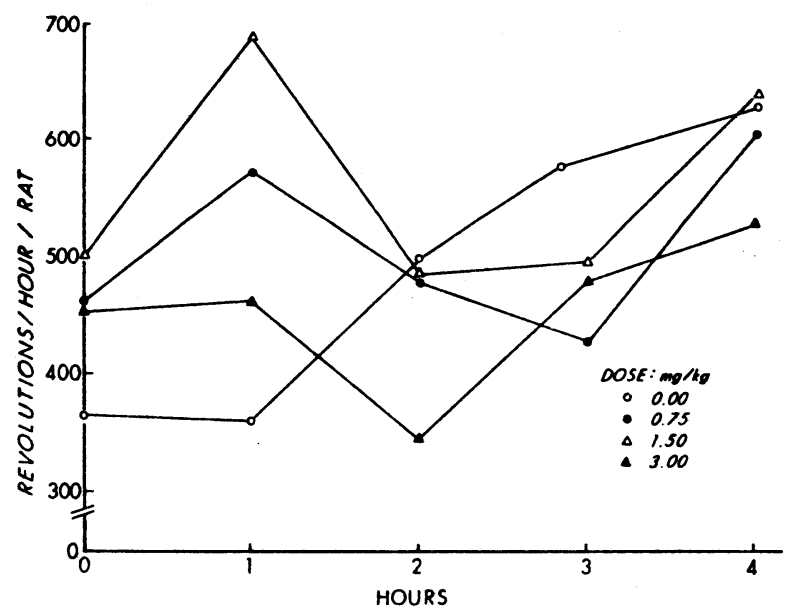

Fig. 1. Wheel running of rats as a function of dose of methamphetamine and hours after injection, averaged across predeprivation running levels and food deprivation. less than the $80 \%$ weight group $(t=4.02, d f=24$, $\mathrm{p}<.01)$ and the $70 \%$ weight group $(\mathrm{t}=5.57, \mathrm{df}=24$, $\mathrm{p}<.01)$. The two latter deprivation groups did not differ between themselves with respect to this measure. The respective means were $285.5,558.9$, and $665.2 \mathrm{rph}$.

\section{DISCUSSION}

The purpose of this experiment was to determine the time course and peak effects of methamphetamine on wheel-running activity of food-deprived rats and to determine whether degree of food deprivation and/or predeprivation levels interact with dosage to influence running activity. The results indicate that the peak effects of methamphetamine on this form of behavior occur with a dose of $1.50 \mathrm{mg} / \mathrm{kg}$ and are proportional to the effects of initial levels and/or deprivation. These results are consistent with those of Irwin, Slabok, \& Thomas (1958), who found that a dose of $2 \mathrm{mg} / \mathrm{kg}$ of methamphetamine injected subcutaneously increased wheel revolutions per $2 \mathrm{~h}$ emitted by nonfasted Carworth rats. In the present experiment, an increase of dose from $1.50 \mathrm{mg} / \mathrm{kg}$ to $3.00 \mathrm{mg} / \mathrm{kg}$ resulted in a return of activity to levels that did not differ from those of the group receiving $0 \mathrm{mg} / \mathrm{kg}$. These latter results are consistent with those of Yagi (1963), who reported that $3.00 \mathrm{mg} / \mathrm{kg}$ methamphetamine increased wheel running of male albino rats but $6.00 \mathrm{mg} / \mathrm{kg}$ decreased the running. The differences in doses that produce peak effects are probably due to procedural differences between the latter two studies.

The results further indicate that the effects of $1.50 \mathrm{mg} / \mathrm{kg}$ of the drug occur during the first hour after injection and are over by the second hour. These results are consistent with those of Yagi (1963), who found that $3.0 \mathrm{mg} / \mathrm{kg}$ of methamphetamine exerted its peak effect on running-wheel activity of nonfasted rats during the first hour, although the effects were evident for up to $4 \mathrm{~h}$. The results for both of these studies are consistent with those of Sulser, Owens, Norwich, \& Dingell (1968), who used the Williamson ultrasonic cage, and Farner (1962), who used a photocell cage, to measure the effects of amphetamine on activity. The increase in running under the $0.00 \mathrm{mg} / \mathrm{kg}$ condition between Hours 1 and 4 is consistent with the findings of Finger, Reid, \& Weasner (1957) and Jakubczak (1969). These authors found marked increases in running of food-deprived rats prior to a regularly scheduled feeding, even though an hour intervened between removal from the drum and feeding. Nevertheless, the present experiment indicates that such an anticipatory increase in running is proportional to the effects of predeprivational levels of activity and degree of food deprivation.

Finally, the results of this experiment fail to provide evidence that the effects of increasing doses of methamphetamine on wheel running of food-deprived rats interact with degree of food deprivation, as suggested by Cole (1967), or with individual differences in initial levels of activity, as suggested by Irwin et al (1958). Within the sensitivity of this experiment, the effects of deprivation and initial levels on running were additive with those of dose of methamphetamine. Recently Fibiger \& Campbell (1971) reported a potentiation of the effect of amphetamine on stabilimeter activity by starvation. The discrepancy between the results of the present study and those of the latter one may be due to differences in measuring devices, kind of deprivation schedule, or task requirement.

\section{REFERENCES}

Cole, S. O. Further study of interactive effects of amphetamine and food deprivation. Psychological Reports, 1965, 16, 625-630.

Cole, S. O. Experimental effects of amphetamine: A review. Psychological Bulletin, 1967, 68, 81-90.

Cole, S. O. Experimental effects of amphetamine: Supplementary report. Perceptual Motor Skills, 1970, 31, 223-232.

Franer, D. Die wiekung von amphetamin und Hexobarbital auf junge und alte ratten. Gerontologia, 1960, 4, 144-153. 
Fibiger, H. C., \& Campbell, B. A. Potentiation amphetamine-induced arousal by starvation. Proceedings of 79th Annual American Psychological Association Convention, 1971, 6, 771-772.

Finger, F. W., Reid, L. S., \& Weasner, M. H. The effect of reinforcement upon activity during cyclic food deprivation. Journal of Comparative \& Physiological Psychology, 1957, 50, 495-498.

Irwin, S., Slabok, M., \& Thomas, G. Individual differences: I. Correlation between control locomotor activity and sensitivity to stimulant and depressant drugs. Journal of Pharmacological Experimental Therapy, 1958, 123, 206-211.

Jakubczak, L. F. Effects of blood-glucose levels on wheel-running activity of food-deprived rats. Psychonomic Science, 1969, 16, 157-158.
Sulser, F, Owens, M. L., Norwich, M. R., \& Dingell, J. V. The relative role of storage and synthesis of brain norepinephrine in psychomotor stimulation evoked by amphetamine or by desipramine and tetrabenazine. Psychopharmacologia (Berlin), 1968, 12, 322-332.

Winer, B. Statistical principles in experimental design. 2nd ed. New York: McGraw-Hill, 1971.

Yagi, B. Studies in general activity: II. The effect of methamphetamine. Annals of Animal Psychology, 1963, 13, 37-47.

(Received for publication February 26, 1973.) 